Coloni, R.D. Óleos vegetais na alimentação de poedeiras. PUBVET, Londrina, V. 2, N. 42, Art\#397, Out4, 2008.

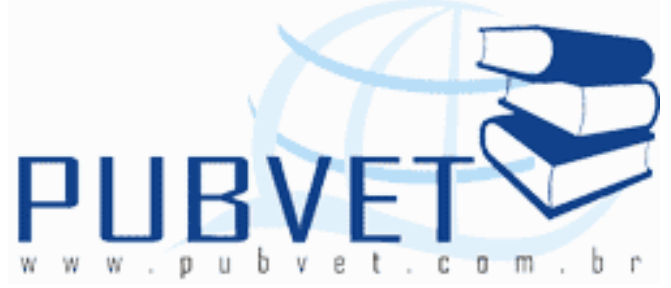

PUBVET, Publicações em Medicina Veterinária e Zootecnia.

Disponível em: <https://doi.org/10.31533/pubvet.v02n10a397>.

\title{
Óleos vegetais na alimentação de poedeiras
}

\section{Rodrigo Dias Coloni}

Aluno de Pós-graduação, nível de mestrado, Faculdade de Ciências Agrárias e Veterinárias, Campus de Jaboticabal, Departamento de Zootecnia, área de nutrição e produção animal.

\section{RESUMO}

Dentro da cadeia produtiva atual, a suinocultura e principalmente a avicultura, apresentam um desenvolvimento tecnológico de grande velocidade. Dentro desse contexto, é importante que fatores como nutrição, genética e sanidade caminhem juntos para que obtenhamos um funcionamento adequado. Na área da nutrição animal, é muito importante nos atentarmos não só pela questão da quantidade más também, pelo caráter da qualidade dos ingredientes que estamos utilizando na formulação de rações. Uma das qualidades de uma dieta está voltada para a característica da energia cuja presença, determina o desempenho da criação, principalmente em aves. A utilização de óleos e gorduras na alimentação de aves apresentam como características, um aumento da energia das rações, melhoram a palatabilidade dos alimentos além de melhorar a digestão e absorção de constituintes não lipídicos dos 
Coloni, R.D. Óleos vegetais na alimentação de poedeiras. PUBVET, Londrina, V. 2, N. 42, Art\#397, Out4, 2008.

ingredientes. Os óleos de origem vegetal mais utilizados dentro da nutrição de monogástricos são: óleo de soja, óleo de girassol, óleo de algodão, óleo de linhaça e óleo de canola. Essas substâncias energéticas nas rações para poedeiras podem contribuir de forma benéfica para o peso dos ovos e da gemas, porém, não contribuem para um ganho de peso das aves, o que julgamos ideal já que as poedeiras necessitam ser mais leves para não comprometer a postura.

PALAVRAS-CHAVE: óleos vegetais, energia, dieta, ovos.

\section{Vegetable oils in power of poedeiras}

\section{ABSTRACT}

Within the current production chain, mainly to poultry and swine, have a technological development of high speed. In this context, it is important that such factors as nutrition, genetics and health go together to get a proper functioning. In the area of animal nutrition is very important to look not only the question of quantity but also by the character of the quality of the ingredients that we use in formulating diets. One of the qualities of a diet is focused on energy feature whose presence, determines the performance of creation, mainly in birds. The use of oils and fats in the diet of birds have as characteristics, an increase of feed energy, improve the palatability of food in addition to improving the digestion and absorption of the non-lipid ingredients. The more of vegetable oils used in the nutrition of monogastric are: soybean oil, sunflower oil, cotton oil, flaxseed oil and canola oil. These substances in feed for laying hens energy can play a beneficial to the weight of the eggs and yolks, however, do not contribute to a weight gain of birds, which we consider ideal because the layers need to be lighter not to compromise the position. KEY WORDS: vegetable oil, energy, diet, eggs. 
Coloni, R.D. Óleos vegetais na alimentação de poedeiras. PUBVET, Londrina, V. 2, N. 42, Art\#397, Out4, 2008.

\section{INTRODUÇÃO}

Os óleos e gorduras constituem excelentes fontes de ingredientes energéticos na alimentação para aves. Devemos ter atenção quanto à adição dessas substâncias nas dietas, pois, concentrações elevadas podem acarretar problemas em produção dos animais. Além disso, esse excesso de energia na dieta ocasiona menor ingestão de ração e pode levar esse animal a um acúmulo de gordura corporal (DUARTE et al., 2004).

Os óleos vegetais são importantes fontes de ácidos graxos insaturados como os ácidos oléico, linoléico e linolênico; diferindo significativamente em relação às gorduras de origem animal as quais são ricas em ácidos graxos saturados (MORITA, 1992). Existem substâncias ricas em ácidos graxos insaturados que são os lipídeos, os quais são muito susceptíveis aos processos de oxidação. Essa mesma oxidação causa perda da qualidade da ração afetando seu sabor, aroma, cor, textura além da produção de alguns compostos tóxicos; dessa maneira, deve-se tomar bastante cuidado na adição dessas substâncias nas rações (SCOTT et al., 1982).

De acordo com alguns trabalhos, têm-se resultados positivos onde quando da inclusão de óleo na ração, ocorre uma melhora da intensidade da cor da gema, melhora a porcentagem de postura, aumento na massa de ovos além de, aumentar o peso dos ovos e proporciona melhoria do albúmen e das gemas (GROBAS et al., 1997).

\section{CARACTERÍSTICAS E IMPORTÂNCIA DE CADA ÓLEO}

\section{ÓLEO DE SOJA}

O Brasil é um dos principais países do mundo em produção de soja além dos Estados Unidos, Argentina e China. No Brasil, as principais áreas produtoras estão na região Sul, Sudeste e Centro-Oeste mais precisamente no Paraná, Rio Grande do Sul, Mato Grosso e Goiás. 
Coloni, R.D. Óleos vegetais na alimentação de poedeiras. PUBVET, Londrina, V. 2, N. 42, Art\#397, Out4, 2008.

Segundo HUI (1996), o óleo de soja é a melhor fonte lipídica para animais jovens, como pintos na fase inicial e leitões desmamados precocemente.

Devido ao seu alto conteúdo em ácidos graxos insaturados, principalmente em ácido linoléico, é importante utilizá-lo em rações para poedeiras por seu efeito positivo sobre o tamanho dos ovos (PENZ, 1991).

\section{ÓLEO DE GIRASSOL}

O girassol é uma das quatro maiores culturas produtoras de óleo vegetal no Brasil.

O óleo de girassol é obtido industrialmente através de um processo de prensagem seguido de uma extração por solvente, geralmente o hexano. É rico em ácidos graxos poliinsaturados e vitamina $\mathrm{E}$, agindo como uma substância antioxidante.

Por muitos autores, dentre eles WHITE (1992), é considerado como um ingrediente com teor de proteína médio e bom valor energético.

\section{ÓLEO DE ALGODÃO}

A semente de algodão contém de 14 a $25 \%$ em média de óleo onde, sua qualidade depende da variedade de condições de clima e solo e também do estágio final de maturação da semente (SOLOMONS, 2002).

Quando de sua extração do caroço feita por solvente, o óleo apresenta boa composição em ácidos graxos com 30\% de ácido oléico e 50\% de ácido linoléico.

Deve-se ter uma atenção especial quanto á questão do gossipol (pigmento amarelo-esverdeado, encontrado nas glândulas de óleo do caroço de algodão), pois, são fatores limitantes nas rações de monogástricos. 
Coloni, R.D. Óleos vegetais na alimentação de poedeiras. PUBVET, Londrina, V. 2, N. 42, Art\#397, Out4, 2008.

As aves de postura podem tolerar níveis de até 200 ppm de gossipol nessa substância energética (HERNANDEZ et al., 1996).

\section{ÓLEO DE LINHAÇA}

O óleo de linhaça é extraído da semente de linho pelo mecanismo de compressão a frio, fato que ajuda na preservação de suas propriedades nutritivas. É um óleo rico em substâncias como ômega-3 além de apresentar uma concentração aproximada de 50\% em ácido linolênico; o que consiste em um incremento importante em rações para poedeiras.

A utilização do óleo de linhaça em altas concentrações em rações para poedeiras pode causar alguns efeitos negativos; dentre eles, propiciar uma diminuição na produção de ovos, pode causar também um sabor desagradável ao ovo devido ao processo oxidativo (MORI, 2001).

\section{ÓLEO DE CANOLA}

Considerado como um ingrediente alternativo que foi desenvolvido a partir do melhoramento da colza.

O óleo de canola é considerado uma fonte acessível aos ácidos graxos essenciais, contendo tanto ômega-3 quanto ômega-6. Esse óleo pode ser utilizado na alimentação animal de forma imediata após sua extração.

É caracterizado por seu alto grau de insaturação com mais de $90 \%$ de ácidos graxos insaturados aliados com altas concentrações em fosfolipídios.

De acordo com trabalhos desenvolvidos por BAUCELLS et al., 2000, verificaram que o desempenho produtivo de poedeiras não foi afetado pelo uso de dietas contendo $4 \%$ de óleo de canola. 
Coloni, R.D. Óleos vegetais na alimentação de poedeiras. PUBVET, Londrina, V. 2, N. 42, Art\#397, Out4, 2008.

\section{REFERÊNCIAS BIBLIOGRÁFICAS}

BAUCELLS, M.D.; CRESPO, N.; BARROETA, A.C. et al. Incorporation of different polyunsaturated fatty acids into eggs.

Poultry Science, v.79, p.51-59, 2000.

DUARTE, K. F.; JUNQUEIRA, O. M.; LAURENTIZ, A. C.; FILARDI, R. S.; CANCHERINI, L. C.; RIBEIRO, P. A. P. Níveis de energia e programas de alimentação sobre o desempenho e características de carcaça de frangos de corte de 42 a 57 dias de idade. In: CONFERÊNCIA APINCO DE CIÊNCIA E TECNOLOGIA AVÍCOLA, 25., Santos, 2004. Anais... Campinas: Apinco, 2004. p. 29.

GROBAS, S.; MENDES, J.; MEDEL, P.; LAZARO R.;MATEOS, G. G. Influence of energy, linoleic acid and fat content of the diet on performance and weight of egg components of brown layers. Poultry Science, v. 76, p. 256, 1997.

HERNANDEZ, M.R.; SAMPAIO, A A M.; TOSI, G. M..; OLIVEIRA, M.D.S.; VIERA, P. F.; KROKAN, N. Avaliação de variedades de cana-de-açúcar através do estudo de desempenho com bovinos de corte. In: Reunião Anual da Soc. Bras. Zoot., Fortaleza, 1996. Anais... Fortalez, CE, 1996. p.88.

HUI, Y. H. Bailey's industrial oil and fat products. New York: John Wiley, v.1, p.19-43, 1996.

MORI, A. V. Utilização de óleo de peixe e linhaça na ração como fontes de ácidos graxos poliinsaturados ômega-3 em ovos de galinhas. São Paulo. 2001. 162f. Tese (Doutorado) - Faculdade de Medicina Veterinária e Zootecnia, Universidade de São Paulo.

MORITA, M.M. Custo $x$ benefício do uso de óleos e gorduras em dietas avícolas. In: CONFERÊNCIA APINCO DE CIÊNCIA E TECNOLOGIA AVÍCOLA, 1992, Santos. Anais... Santos: Apinco, 1992. p.29-35.

PENZ, Jr. A. M. Sorgo e soja integral na aliment. IN: CONFERÊNCIA DE CIÊNCIA E TECNOLOGIA AVÍCOLA, Campinas, 1991. Anais... Associação Brasileira de Produtores de Pintos de Corte, p. 63-73, 1991.

SCOTT, M.L.; NESHEIM, M.C.; YOUNG, R.J. Proteins and amino acids. In: Nutrition of the chicken. 3.ed. Ithaca: M.L. Scott \& Associates, 1982. p.58.

SOLOMONS, T. W.; Química Orgânica. Ed. LTC. Rio de Janeiro, 2002.

WHITE, P. J. Fatty acids in oilseeds (vegetable oils). In: CHOW, C. K. Fatty acids in foods and their health implications. New York: Marcel Dekker, p.237-242, 1992. 